\title{
The effect of health shocks on labour market outcomes in Russia
}

\author{
Ekaterina Aleksandrova, Venera Bagranova and Christopher J. Gerry ${ }^{\star}$
}

\begin{abstract}
This study examines the effects of individual health shocks on labour market outcomes in the Russian Federation during the period 2000-2018. Employing data from the Russia Longitudinal Monitoring Survey-Higher School of Economics, we demonstrate that adverse health shocks have negative consequences for employment, wages, and income. We find that the effects are strongest for males, the less educated, those on lower incomes, those in middle-ranking and professional occupations, and for those experiencing the most severe health shocks. However, consistent with our knowledge of the Russian labour market, we also observe that the wage and income elasticities are considerably higher than the employment elasticities and above those reported for other countries. Understanding how to attenuate the negative labour market consequences associated with health shocks is paramount and we, therefore, consider the potential role that labour, health and social policies can play in mitigating risk.
\end{abstract}

Key words: Health shocks, Employment, Wages, Income, Russia

FEL classification: $\mathrm{C} 23, \mathrm{I} 12, \mathrm{~J} 60$

\section{Introduction}

Since the fall of the Soviet Union, Russia has experienced a sustained demographic decline, unprecedented fluctuations in mortality rates and the continuation of a long-term relative deterioration in health, driven by a rapid growth in chronic disease and multimorbidity. These developments have been associated with a precipitous fall in the working-age population (Au et al., 2005), major challenges to the reform of social welfare and the emergence of unconventional labour market institutions accompanying the industrial transformation that has taken place during the last three decades (Lehmann and Muravyev, 2012; Slonimczyk and Gimpelson, 2015). While all of these phenomena attracted headlines and scholarly scrutiny during the 1990s and

Manuscript received 23 November 2020; final version received 6 July 2021.

Address for correspondence: Christopher J. Gerry, Oxford School of Global and Area Studies, University of Oxford, 12 bevington Road, Oxford, OX2 6LH, UK, email: christopher.gerry@area.ox.ac.uk

${ }^{\star}$ National Research University Higher School of Economics, St. Petersburg (EA, VB); University of Oxford (CJG). We are grateful to the participants of seminars at National Research University Higher School of Economics in Moscow and St. Petersburg for helpful comments made during the early stages of this work. This work was supported by the Russian Science Foundation under grant No. 20-18-00307, 'Health of the Nation: the multidimensional analysis of Health, Health Inequality and Health-related Quality of Life'. 
early 2000s, less attention has been paid to the effects of more recent policy responses, which have included reforms to the pension age (Logvinenko, 2020), the introduction of maternity capital (Slonimczyk and Yurko, 2014; Sorvachev and Yakovlev, 2020), and wide-ranging anti-tobacco and alcohol laws as part of ambitious national health and demographic programmes (Cook, 2015).

There are myriad reasons to be concerned about the functioning of the labour market in any country but, while not the explicit focus of social or health policies, the Russian labour market sits at the interface of long-term challenges relating to industrial restructuring, social welfare reform, health and population dynamics (Gerry, 2021). Individual labour market participants face the possibility of large and persistent financial consequences for themselves and their families (Angelini et al., 2009; GarciaGomez et al., 2013; Zwysen, 2015). As well as securing material well-being and physical health, stable employment can also protect mental health, boost self-esteem, and provide opportunities for developing social networks that underpin community and promote social inclusion. Beyond the individual effects, the prolongation of working lives is necessary to facilitate and render sustainable the ongoing pension reforms in Russia as well as to provide a counter to demographic challenges.

For Russia, as elsewhere, the nature and dynamics of these relationships are complex but the association between health and the labour market is now a recognised line of enquiry in the economics literature (Bound and Burkhauser, 1999; Currie and Madrian, 1999) with a particular focus on unpicking the impact that 'shocks' to health can have on labour activity. Unanticipated changes in individual health do not only impact the capacity to work per se but also affect labour productivity, wage income and, via healthcare costs, overall household disposable income. Indeed, the negative association between shocks to health and labour market outcomes is now a well-established finding in the health and labour economics literatures, supported by evidence from both advanced and emerging economies (Bound et al., 1999; Disney et al., 2006; Jones et al., 2010, 2020; Zucchelli et al., 2010; Garcia-Gomez et al., 2013; Lindeboom et al., 2016; Lenhart, 2019). As we enter a new health-economy paradigm, governed by the prospect of pandemics, understanding the relationship between health shocks and labour market activity will only become more important.

In view of Russia's unusual institutional constellation and extreme health and demographic challenges, it is surprising that there has been so little attention paid to this relationship so far. ${ }^{1}$ We address this lacuna and, in doing so, make three fundamental contributions. First, we provide evidence of the impact of health shocks on employment and remuneration in the Russian labour market. Second, we explore gender and socioeconomic asymmetries in these effects. Third, we interpret these findings in the unique institutional context that frames the health-labour market relationship in Russia.

Using longitudinal household data and an econometric strategy proposed by García-Gómez and López-Nicolás (2006) and further developed by Lenhart (2019), we find that adverse health changes have negative consequences for wages, income and the probability of remaining employed. In particular, we find that the probability

\footnotetext{
${ }^{1}$ Goryakin and Suhrcke (2017), provide an interesting related analsyis of the link between health and labour supply in Russia using the same data as we utilise. However, their study is substantially different as it focuses only on the quantity of labour supplied, does not consider health shocks and is based on a different econometric strategy.
} 
of staying in work following a health deterioration reduced by $2 \%$ in the year after a health shock. Additionally, adverse health shocks are associated with $17 \%$ and $6-12 \%$ reductions in personal income and wages, respectively. The matching estimates also reveal gender asymmetry in the effects: males experience a $2 \%$ reduction in employment probability and a $22 \%$ fall in income, while women appear not to bear any burden in these categories. In contrast, the expected salary reductions are similar. We find that the less educated, those on lower incomes, and those in middle-ranking and skilled occupations, are more vulnerable to health shocks. Finally, more severe health shocks are associated with much more prominent losses in employment and income (though not wages), to the magnitude of 6 (7) and 40 (0)\% reductions in, respectively, the probability of retaining employment and personal income for males (females). These findings, that Russian citizens experiencing negative health shocks, will feel the labour market effects at the extensive, rather than intensive margin, and that the effects are not distributed neutrally according to socioeconomic characteristics, are consistent with what we know about the evolution of the price-flexible Russian labour market and the pervasive inequalities in income and health in Russia.

Section 2 explains the relevant background in terms of the existing literature and the unique Russian context. Section 3 describes the data and the empirical strategy, while section 4 and 5 respectively present and discuss the main results. Section 6 concludes and considers the policy implications of our findings.

\section{Background}

\subsection{The literature}

There is now a wealth of empirical evidence detailing the relationship between deteriorating health and labour market outcomes. Many of these studies have been concerned with the labour market choices and outcomes of those approaching or beyond official pension age (Au et al., 2005; Disney et al., 2006; Zucchelli et al., 2010). Increasingly though, attention is now being focused on the general working population and evidence confirming the generality of the findings now exists for a wide range of countries, including Spain (García-Gómez and López-Nicolás, 2006), China (Lindelow and Wagstaff, 2005), Sweden (Lundborg et al., 2015), Australia (Zucchelli et al., 2010), United Kingdom (Disney et al., 2006; García-Gómez et al., 2010) and the Netherlands (García-Gómez et al., 2013). These studies typically focus on single countries because the country-specific social welfare, public health and labour market institutions are understood to frame the labour market decisions taken in response to adverse health changes (García-Gómez and López-Nicolás, 2006; García-Gómez, 2011; Gupta et al., 2015).

Given the challenges posed by endogeneity, unobserved preferences and the possibility of justification bias in self-assessed variables, establishing reliable estimates of the effect of changes in health on labour market events and outcomes is far from straightforward. Previous studies have addressed these issues using a wide range of empirical strategies including approaches that: exploit the onset of health conditions (GarcíaGómez, 2011), acute admissions (Mitra et al., 2016) and unplanned hospitalisations (García-Gómez et al., 2013); use accidents and injuries as exogenous health shock variables (Dano, 2005; Zucchelli et al., 2010; Halla and Zweimüller, 2013; Lindeboom et al., 2016) and; treat the incidence of cancer, stroke, or myocardial infarction as evidence of severe health shocks (Gupta et al., 2015; Trevisan and Zantomio, 2016). 
From this growing body of evidence, we cull a number of lessons. First, while a strong empirical relationship between health shocks and labour market outcomes has been established, identifying the complex causal mechanisms underpinning the relationship remains elusive. Second, from this, it follows that the nature and scale of the relationship are ambiguous, with the impact of health shocks on employment, wages and income dependent on the institutional specificities of the labour market, public infrastructure and government policies. Third, the relationship also varies according to key demographic and socioeconomic characteristics, including age, gender and income, as well as being conditioned by the nature and severity of the health shock.

\subsection{Russian labour market and demographics}

In view of these lessons it is instructive to reflect on the unique circumstances and evolution of the Russian labour market in the context of an economy that has experienced large macroeconomic shocks (in 2009 and 2014), and that faces a challenging demographic crisis associated with a long term stagnation in health outcomes, perforated only by unprecedented spikes in mortality in the early and late 1990s and a sustained rebound during the 2000s. Figure 1 captures some of the consequent labour market dynamics during the period under study. In particular, note how the $7.8 \%$ fall in GDP per capita in 2009 is accompanied by a much more modest $1.9 \%$ drop in employment, and a $3.5 \%$ decline in real wages. This phenomenon of negligible employment elasticities alongside greater volatility in wages and working hours is a well-documented characteristic of the Russian labour market dating back to the early 1990s (Gimpelson and Kapeliushnikov, 2013). Indeed, the Russian aggregate employment elasticity of 0.24 is around half of that (0.47) typically observed in European countries (ECB Economic Bulletin, 2016).

Over the same period, Russia's health and demographic profile has remained unfavourable, even if not as catastrophic as in the 1990s. The total population has declined from 146.6 million in 2000 to 144.5 million in 2018, while the proportion of the

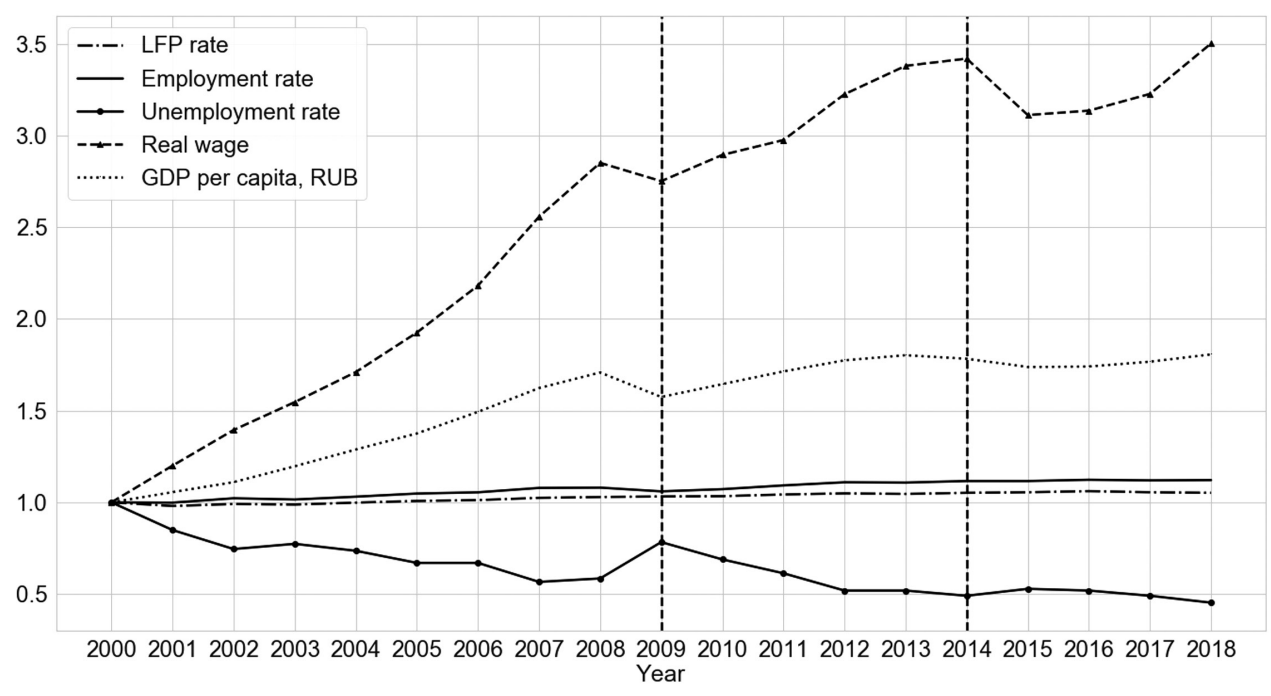

Fig. 1. GDP per capita, Labour Force Participation (LFP) rate, employment rate, unemployment rate and real wage in Russia, 2000-2018 (2000 = base year). Source: https://www.gks.ru/. 
working-age population has fallen from 72.1 to $67.6 \%$. These developments contrast with the corresponding dynamics recorded for other OECD countries (OECD, 2020). Despite some improvements in the public health environment, Russia continues to rank poorly in most health metrics compared to OECD and emerging (BRICS) economies. For example, while male (female) life expectancy in Russia was 68 (78) in 2018, the corresponding figures were 72 and 79 in Brazil, and 75 and 79 in China (World Bank, 2020). Particularly noteworthy therefore is the high gender gap in life expectancy, which exceeds that found in comparable countries.

Underlying this poor health profile is a pandemic of chronic disease linked to the absence of the 'cardiovascular revolution' that western European countries underwent in the 1960s and 1970s (Denisova and Shapiro, 2013). Chronic diseases account for almost $90 \%$ of all deaths in Russia and the average Russian faces a 30\% probability of dying from cancer, diabetes, cardiovascular disease or chronic respiratory diseases between the ages of 30 and 70 (Kaneva et al., 2018; World Health Organisation, 2018). Moreover, the probability of dying from these causes of death in Russia is strongly biased towards younger ages in comparison with more advanced economies (Denisova and Shapiro, 2013). During the last decade, the Russian authorities have initiated concerted efforts to improve population health, including through impressive legislative initiatives targeting alcohol and tobacco but, even with these measures, Russia remains a world 'leader' in tobacco and alcohol consumption, traits particularly prevalent among middle and older aged males (OECD, 2020).

\section{Materials and methods}

\subsection{The data}

This research is based on data drawn from rounds 9 to 27 (2000 to 2018) of the Russia Longitudinal Monitoring Survey-Higher School of Economics (RLMS-HSE), which is a nationally representative panel survey developed to monitor the economic welfare and health of households and individuals in the Russian Federation. The RLMS-HSE provides a wide-ranging set of characteristics relating to the labour market (e.g. formal and informal employment, wages, personal and household income, working hours) and health (e.g. self-assessed health, BMI, chronic conditions, acute events).

We exploit a standard self-assessed health (SAH) survey question offering five possible responses (very good, good, average, bad, very bad) to the question 'How do you assess your health?'. We identify a negative health shock occurring when an individual follows the report of good or very good health (Good) in one period with a self-assessment of average, bad or very bad (Bad) in the subsequent period. While this represents what we term a 'standard' health shock, we also identify 'severe' health shocks as those involving a drop in health status of at least two levels. Positive health shocks are measured following the reverse algorithm. Self-evidently, these health shocks, as defined, may take place at any point during the period between surveys and there may have been further movements in health during that period, which remain unobserved.

Since, we are interested in linking these observed changes in health to changes in labour market outcomes, in addition to defining both mild and severe shocks, we construct what become 'control' and 'treatment' groups in our analysis very cautiously. First, we observe individuals across 17 three-year sequences, denoted $t^{-1}, t^{0}$ and $t^{+1}$, between 2000 and 2018. Each individual retained in the sample is in very good or good 
health in $t^{-1}$, is employed and is in receipt of wages in $t^{-1}$ and $t^{0}$. The control group are those individuals that report good health throughout the sequence and therefore have a reporting sequence of Good, Good, Good (GGG). The treatment group are those who experience a sustained health shock after $t^{-1}$, and therefore have a reporting sequence of Good, Bad, Bad (GBB). The labour market outcome variables are employment status, monthly income from labour and non-labour earnings (log) and monthly wage earnings (log).

Table 1 provides the key descriptive statistics for the resultant sample, including the main patterns of health status by age group and gender. For the sample overall $34.7 \%$ report being in good or very good health, with the majority $(54.8 \%)$ reporting average health. Unsurprisingly, among the oldest age groups the proportion reporting good or very good health falls to under one-fifth and, as in surveys elsewhere, males self-report better health status than females. We observe that $8.9 \%(8.3 \%)$ of individuals experience a negative (positive) health change and that the majority of these are of the less severe variety. The second part of Table 1 indicates the incidence of eight common 3-year health sequences, including the control (GGG) and treatment (GBB) groups. The control group response is substantially more common among the two youngest age groups and, in keeping with this, so too is a temporary health shock (Good, Bad, Good: GBG). In contrast, respondents reporting the GBB sequence are more evenly distributed by age group. Consistent with these observations, the younger age groups more often report (sustained) improvements in health (Bad, Good, Good: BGG).

Table 1. Health-related descriptive statistics across age groups and gender

\begin{tabular}{lllllll}
\hline & $18-29$ & $30-45$ & $46-72$ & Female & Male & Total \\
\hline Very bad health & 0.002 & 0.003 & 0.021 & 0.012 & 0.009 & 0.010 \\
Bad health & 0.022 & 0.044 & 0.176 & 0.110 & 0.076 & 0.095 \\
Fair health (neither bad nor good) & 0.385 & 0.528 & 0.654 & 0.582 & 0.501 & 0.548 \\
Good health & 0.553 & 0.409 & 0.145 & 0.285 & 0.391 & 0.330 \\
Very good health & 0.039 & 0.016 & 0.004 & 0.012 & 0.023 & 0.017 \\
Negative health change & 0.100 & 0.112 & 0.065 & 0.081 & 0.099 & 0.089 \\
Severe & 0.006 & 0.006 & 0.005 & 0.004 & 0.006 & 0.005 \\
Mild & 0.096 & 0.107 & 0.061 & 0.078 & 0.094 & 0.084 \\
Positive health change & 0.100 & 0.104 & 0.058 & 0.078 & 0.090 & 0.083 \\
Severe & 0.005 & 0.004 & 0.003 & 0.003 & 0.005 & 0.004 \\
Mild & 0.096 & 0.101 & 0.055 & 0.075 & 0.087 & 0.080 \\
$N$ & 47,897 & 66,043 & 85,257 & 113,893 & 85,304 & 199,197 \\
GBB & 0.106 & 0.122 & 0.105 & 0.106 & 0.118 & 0.111 \\
GBB mild & 0.101 & 0.116 & 0.097 & 0.101 & 0.111 & 0.105 \\
GBB severe & 0.005 & 0.006 & 0.008 & 0.006 & 0.007 & 0.006 \\
GGG (control group) & 0.241 & 0.140 & 0.041 & 0.112 & 0.159 & 0.133 \\
GBG & 0.088 & 0.76 & 0.037 & 0.060 & 0.073 & 0.065 \\
GGB & 0.112 & 0.106 & 0.056 & 0.081 & 0.100 & 0.090 \\
BGG & 0.114 & 0.098 & 0.050 & 0.081 & 0.091 & 0.086 \\
BGG severe & 0.005 & 0.004 & 0.002 & 0.003 & 0.004 & 0.003 \\
BGG mild & 0.110 & 0.095 & 0.048 & 0.079 & 0.087 & 0.082 \\
BGB & 0.079 & 0.093 & 0.080 & 0.083 & 0.086 & 0.084 \\
BBG & 0.103 & 0.109 & 0.087 & 0.101 & 0.098 & 0.099 \\
BBB & 0.158 & 0.255 & 0.545 & 0.376 & 0.275 & 0.332 \\
$N$ & 20,660 & 27,097 & 26,600 & 41,876 & 32,481 & 74,357 \\
\hline
\end{tabular}


Unsurprisingly, more elderly respondents are considerably more likely to report a Bad, $\mathrm{Bad}, \mathrm{Bad}(\mathrm{BBB})$ sequence, as too are females.

Before moving on to our empirical strategy, a note about the SAH data on which our analysis is grounded. It is well-documented that SAH can be a reliable proxy for mortality and morbidity (Kaplan and Camacho, 1983; Idler and Benyamini, 1997) but equally that it can be subject to reference bias, measurement error and reporting heterogeneity (Shmueli, 2003; Pfarr et al., 2012). Supplementary Appendix Table A1, showing how our constructed health shock is correlated with more objective health events, further explores the appropriateness of SAH as a means for capturing health shocks. We find that the probability of experiencing a health shock or reporting bad health is strongly correlated with the probability of experiencing a heart attack or stroke, making an ambulance call, missing a certain number of days at work due to health problems, and reporting lower values of the well-regarded EuroQoL group health metric, the EQ-5D index (Devlin et al., 2020). We also present the correlation of SAH and shocks in SAH with the incidence of several chronic conditions. As expected, there is little evidence that conditions that are chronic and persistent are correlated with health shocks even though they are strongly correlated with the prevailing levels of SAH. Finally, with respect to the issues related to reporting heterogeneity - these are less of a concern for this research since the health states are only being compared within individuals rather than between individuals or sub-groups.

\subsection{Empirical strategy}

Following García-Gómez and López-Nicolás (2006) and Lenhart (2019) we implement a difference-in-difference framework using three different propensity score matching techniques to explore the effect of health shocks on labour market outcomes (employment, personal income and monthly wages). Specifically, we use kernel matching on the propensity score; nearest neighbour matching on the propensity score (four nearest neighbours); and nearest neighbour matching on the set of covariates based on the Mahalanobis distance (four nearest neighbours) to estimate the Average Treatment Effect on the Treated (ATET). We estimate this for the whole sample as well as sub-samples defined by age group, severity of shock and time period. Supplementary Appendix Table records the number of observations in each case.

The ATET compares how the outcome variable changes on average for those who have experienced a health deterioration (GBB) relative to those who have not (GGG). In essence, we use propensity scores, measured as the probability of being in the treated group (GBB), given a vector of conditioning variables (gender, age, settlement type, education level, marital status, number of children, occupation and the logarithm of personal income), to match individuals from this group with similar individuals from the control group (GGG). Additionally, to capture any unobserved heterogeneity across time (with the nearest neighbour matching on the set of covariates), we use exact matching on the year of the shock. The propensity scores are based on the pretreatment covariates and are estimated using the probit model. This methodology allows us to further attenuate the problem of unobserved heterogeneity (García-Gómez and López-Nicolás, 2006) by first differencing the outcome variables to eliminate any unobservable fixed effects that influence assignment to the treatment group. To further account for the possible simultaneous determination of the health shock and 
employment, we restrict our sample to respondents who are initially employed, thus ensuring the treatment occurs before any changes in employment, personal income or wage. $^{2}$

Supplementary Appendix Figures A1 and A2, visually explore the critical 'parallel trends' assumption that, in the absence of a health shock, the difference between the treatment and control groups is constant over time. Reassuringly, for both income and wages we find no evidence of statistically significant differences during the two years $\left(t^{-2}\right.$ and $\left.t^{-1}\right)$ prior to the health shock. Further, Supplementary Appendix Figure A3 demonstrates that the overlap requirement-that it is possible for observations to be selected into either the control or treated group across different covariate combinations, is also satisfied. Indeed, Supplementary Appendix Table A3 indicates that the matching process successfully balances the covariates used in predicting the propensity score. ${ }^{3}$ Finally, the matching methodology is based on a strong identifying assumption, known as the conditional independence assumption (CIA), which demands that there should be no unobserved variables simultaneously influencing the treatment and outcome variables. This important assumption is not directly testable so we address it separately and in detail in section 4 .

\section{Results}

\subsection{Employment}

For ease of exposition, in the main text, we present only the kernel propensity score matching results, noting that there are no qualitative differences across the different methods and that the results, by gender and age group, for the alternative methods are presented in Supplementary Appendix Tables A4-A6. Table 2 presents the differencein-difference effects of SAH shocks on the probability of remaining in employment, by age and period subgroups, separately for males and females. We find that health shocks have a statistically significant negative employment effect for males, reducing the likelihood of retaining employment by $2.1 \%$. The age and time effects suggest that the impact is driven by older workers and particularly by those over 45 years, for whom the effect is observed most strongly over the aggregate period. We find no compelling evidence of an employment effect for females.

\subsection{Personal income}

The consequences of a deterioration in health for personal income are much more prominent. For males, Table 3 provides evidence associating a health shock with a $22 \%$ loss in personal income. This effect is mostly concentrated among individuals below 46 years old with those aged 18-29 and 30-45, respectively, facing 37\% and $25 \%$ income reductions. The estimates for females show that during and after the global economic crisis those aged 30-45 and 46-72 lose almost one-third of their income, while in the period before the crisis kernel matching estimates find no evidence of an effect.

\footnotetext{
${ }^{2}$ By assumption, we rule out the possibility of anticipation effects through which respondents, in expectation of a deterioration in health, decide to transit into unemployment one period in advance.

3 These estimates indicate that unskilled workers over 46 years old, who live in a city, who completed only high school education, have one child in their household, and have lower wages and income are more likely to experience a health shock.
} 
Table 2. ATET on employment of a standard health shock

\begin{tabular}{ccccc}
\hline & $18-29$ & $30-45$ & $46-72$ & $18-72$ \\
\hline Male & & & & \\
$2000-2018$ & -0.013 & $-0.014^{\star \star}$ & $-0.043^{\star \star}$ & $-0.021^{\star \star \star}$ \\
& $(0.008)$ & $(0.006)$ & $(0.018)$ & $(0.007)$ \\
$2000-2007$ & -0.013 & $-0.036^{\star \star \star}$ & -0.012 & $-0.023^{\star \star}$ \\
& $(0.023)$ & $(0.014)$ & $(0.039)$ & $(0.012)$ \\
$2008-2010$ & 0.000 & -0.010 & -0.041 & -0.019 \\
& $(0.021)$ & $(0.026)$ & $(0.044)$ & $(0.016)$ \\
$2011-2018$ & -0.017 & 0.000 & -0.045 & -0.019 \\
& $(0.015)$ & $(0.008)$ & $(0.031)$ & $(0.012)$ \\
Female & & & & -0.005 \\
$2000-2018$ & 0.012 & -0.011 & -0.009 & $(0.010)$ \\
& $(0.020)$ & $(0.008)$ & $(0.029)$ & -0.008 \\
$2000-2007$ & 0.007 & $-0.034^{\star \star}$ & 0.042 & $0.012)$ \\
$2008-2010$ & $(0.040)$ & $(0.016)$ & $(0.062)$ & 0.006 \\
& 0.018 & 0.010 & -0.027 & -0.006 \\
$2011-2018$ & $(0.057)$ & $(0.027)$ & $(0.074)$ & $(0.012)$ \\
& 0.011 & -0.001 & -0.001 & $(0.032)$ \\
\hline
\end{tabular}

Bootstrapped standard errors are shown in parentheses.

${ }^{\star \star \star} p<0.01,{ }^{\star \star} p<0.05,{ }^{\star} p<0.1$

Table 3. ATET effects of a health shock on the logarithm of personal income

\begin{tabular}{ccccc}
\hline & $18-29$ & $30-45$ & $46-72$ & $18-72$ \\
\hline Male & & & & \\
$2000-2018$ & $-0.373^{\star \star \star}$ & $-0.254^{\star \star \star}$ & -0.054 & $-0.224^{\star \star \star}$ \\
& $(0.131)$ & $(0.095)$ & $(0.140)$ & $(0.059)$ \\
$2000-2007$ & $-0.406^{\star}$ & -0.285 & -0.104 & $-0.262^{\star}$ \\
& $(0.214)$ & $(0.206)$ & $(0.391)$ & $(0.142)$ \\
$2008-2010$ & -0.330 & -0.332 & -0.533 & $-0.417^{\star \star}$ \\
& $(0.296)$ & $(0.294)$ & $(0.365)$ & $(0.181)$ \\
$2011-2018$ & $-0.407^{\star \star}$ & -0.167 & 0.058 & $-0.188^{\star \star \star}$ \\
Female & $(0.187)$ & $(0.103)$ & $(0.173)$ & $(0.062)$ \\
$2000-2018$ & -0.052 & -0.103 & -0.128 & -0.078 \\
& $(0.126)$ & $(0.085)$ & $(0.093)$ & $(0.059)$ \\
$2000-2007$ & -0.133 & 0.202 & -0.385 & -0.005 \\
$2008-2010$ & $(0.282)$ & $(0.208)$ & $(0.278)$ & $(0.155)$ \\
& 0.186 & $-0.274^{\star}$ & $-0.298^{\star}$ & -0.186 \\
$2011-2018$ & $(0.359)$ & $(0.158)$ & $(0.165)$ & $(0.126)$ \\
& -0.060 & $-0.295^{\star \star \star}$ & 0.076 & $-0.162^{\star \star}$ \\
\hline
\end{tabular}

Bootstrapped standard errors are shown in parentheses.

${ }^{\star \star \star} p<0.01,{ }^{\star \star} p<0.05,{ }^{\star} p<0.1$

\subsection{Wages}

In a similar spirit, Table 4 demonstrates that, for males, a negative health shock is associated with an $8 \%$ reduction in wages and that this effect is concentrated among those under 45 years of age. It also appears to be a phenomenon that emerged during and 
Table 4. ATET effects of a health shock on the logarithm of monthly wage

\begin{tabular}{ccccc}
\hline & $18-29$ & $30-45$ & $46-72$ & $18-72$ \\
\hline Male & & & & \\
$2000-2018$ & $-0.057^{\star \star}$ & $-0.074^{\star \star \star}$ & -0.067 & $-0.076^{\star \star \star}$ \\
& $(0.028)$ & $(0.025)$ & $(0.045)$ & $(0.018)$ \\
$2000-2007$ & -0.093 & -0.073 & -0.067 & $-0.087^{\star}$ \\
& $(0.059)$ & $(0.060)$ & $(0.119)$ & $(0.047)$ \\
$2008-2010$ & 0.030 & -0.045 & -0.189 & $-0.099^{\star \star}$ \\
& $(0.096)$ & $(0.088)$ & $(0.151)$ & $(0.047)$ \\
$2011-2018$ & $-0.105^{\star \star}$ & $-0.054^{\star}$ & -0.036 & $-0.065^{\star \star \star}$ \\
Female & $(0.046)$ & $(0.029)$ & $(0.054)$ & $(0.023)$ \\
$2000-2018$ & -0.017 & -0.003 & $-0.128^{\star \star \star}$ & $-0.041^{\star \star}$ \\
& $(0.039)$ & $(0.027)$ & $(0.046)$ & $(0.019)$ \\
$2000-2007$ & -0.014 & -0.048 & -0.217 & -0.080 \\
$2008-2010$ & $(0.075)$ & $(0.071)$ & $(0.143)$ & $(0.052)$ \\
& 0.129 & -0.049 & -0.127 & -0.070 \\
$2011-2018$ & $(0.104)$ & $(0.065)$ & $(0.172)$ & $(0.051)$ \\
& -0.060 & -0.007 & -0.069 & -0.026 \\
& $(0.060)$ & $(0.036)$ & $(0.063)$ & $(0.029)$ \\
\hline
\end{tabular}

Bootstrapped standard errors are shown in parentheses.

${ }^{\star \star \star} p<0.01,{ }^{\star \star} p<0.05,{ }^{\star} p<0.1$

beyond the global economic crisis. For females, we find a slightly smaller, $4.1 \%$, overall reduction in wages but observe that this is dominated by females in the oldest age category, who lose up to $13 \%$ of their wages due to adverse health shocks.

\subsection{Distribution of effects}

In Table 5 we explore how health shocks lead to heterogenous effects across different population groups. The first part of the table illustrates the differences across occupation type, finding that middle-level and skilled workers experience the largest labour market consequences of health shocks. Specifically, they face a $2.3 \%$ decrease in the probability of retaining employment, a $19-28 \%$ reduction in income, and a $7-8 \%$ fall in wages. We observe no effects for top-level or unskilled workers. The second section of the table shows that respondents without higher education experience reductions in employment $(3-5 \%)$, in income $(30 \%)$, and in wages $(8-10 \%)$. The final part of the table shows that those with personal income below the sample median face more severe consequences than those above the median, including a 3.5\% reduction in employment probability and a $33 \%$ loss in income compared to no effect among those with higher income. Wage loss is shown to be marginally higher $(7.4 \%)$ for those with lower incomes than for those with higher incomes $(5.5 \%)$.

Finally, Table 6 compares mild health shocks and severe health shocks. As expected, the adverse effects on labour market outcomes are generally larger in the case of severe shocks. In the case of employment, severe shocks for males and females give rise to 6 and $7 \%$ reductions in employment probability compared to 2 and $0 \%$ respectively, for the standard shocks. Similarly, for males, income reductions are more pronounced for those who experience severe negative shocks, while for females, neither shock is 
Table 5. ATET of a health shock on labour market outcomes across occupation type, education level and level of personal income (Kernel Propensity estimates)

\begin{tabular}{llll}
\hline & Employment & Log of personal income & Log of wage \\
\hline Top-level workers & -0.001 & -0.038 & -0.025 \\
Middle-level workers & $(0.006)$ & $(0.059)$ & $(0.020)$ \\
Skilled worker & -0.010 & $-0.283^{\star \star \star}$ & $-0.080^{\star \star \star}$ \\
& $(0.017)$ & $(0.072)$ & $(0.028)$ \\
Unskilled worker & $-0.023^{\star \star}$ & $-0.187^{\star \star}$ & $-0.072^{\star \star \star}$ \\
Incomplete high school & $(0.010)$ & $(0.082)$ & $(0.023)$ \\
& -0.043 & -0.261 & -0.045 \\
High school & $(0.027)$ & $(0.248)$ & $0.074)$ \\
Incomplete higher education & $-0.052^{\star \star}$ & -0.180 & $(0.055)$ \\
Higher education & $(0.023)$ & $(0.156)$ & $-0.109^{\star \star \star}$ \\
Below the median of personal income & $-0.027^{\star \star \star}$ & $-0.297^{\star \star \star}$ & $(0.029)$ \\
& $(0.008)$ & $(0.071)$ & $-0.078^{\star \star \star}$ \\
Above the median of personal income & -0.012 & -0.074 & $-0.027)$ \\
& $(0.010)$ & $(0.070)$ & $(0.024)$ \\
& 0.011 & -0.021 & $-0.074^{\star \star}$ \\
\hline
\end{tabular}

Bootstrapped standard errors are shown in parentheses.

${ }^{\star \star \star} p<0.01,{ }^{\star \star} p<0.05,{ }^{\star} p<0.1$

Table 6. ATET of a health shock on labour market outcomes for severe and mild shocks ((Kernel Propensity estimates)

\begin{tabular}{cccc}
\hline & Employment & Personal income & Wage \\
\hline Male & & & \\
Severe & $-0.060^{\star \star}$ & $-0.404^{\star}$ & -0.123 \\
& $(0.029)$ & $(0.227)$ & $(0.081)$ \\
Mild & $-0.020^{\star \star \star}$ & $-0.218^{\star \star \star}$ & $-0.075^{\star \star \star}$ \\
Female & $(0.006)$ & $(0.057)$ & $(0.022)$ \\
Severe & $-0.071^{\star}$ & -0.352 & -0.073 \\
Mild & $(0.041)$ & $(0.263)$ & $(0.076)$ \\
& -0.002 & -0.067 & $-0.041^{\star}$ \\
& $(0.010)$ & $(0.057)$ & $(0.022)$ \\
\hline
\end{tabular}

Bootstrapped standard errors are shown in parentheses.

${ }^{\star \star \star} p<0.01,{ }^{\star \star} p<0.05,{ }^{\star} p<0.1$

statistically significant. In the case of wage effects, only the less severe health shocks exhibit a negative effect on monthly wages, both for males and females.

\subsection{Sensitivity analysis}

As stated in section 3, the CIA requires that all relevant information is accounted for in the matching process. This assumption is not directly testable so we explore 
it through two channels. First, we go back to the RLMS data and re-estimate our models with additional labour market information, albeit at the cost of sacrificing a significant proportion of our observations. Second, we present the results of a Rosenbaum bounds sensitivity analysis, which allows us to determine how strongly an unobserved variable must affect selection into the treatment group in order to undermine the matching process. With regard to the former, we add two new labour market variables to enhance the richness of the matching information used by drawing on labour market characteristics that may plausibly be related to health shocks. First, the ratio of actual to potential work experience, calculated with reference to the time between the interview date and the date of graduation, may capture a link arising because lower labour market experience is a result of health shocks. Second, whether the individual is employed in the public or private sector, will pick up the effects of sectoral differentials in public-private health outcomes. While the RLMS data does allow us to incorporate this information, it only does so at the cost of sacrificing approximately a significant proportion of our main sample and requires us to make additional assumptions and inferences regarding the sector and potential labour market experience respectively.

Notwithstanding these caveats, Supplementary Appendix Tables A7 and A8 present the results for income, employment, wages and severity of shock for the full-time period, 2000-18. For males, the results are qualitatively similar, though the size of the impacts on income and wage appear smaller, while a severe shock is no longer significant, an effect we put down to the smaller sample size. For females, the differences are greater as we now find some evidence of a significant income effect (including for both severe and mild shocks) and a suggestion that the original estimate of the wage effect may be an underestimate. While there is not sufficient evidence here to alter our main findings, we note that these additional labour market variables may be capturing some female-specific effects, consistent with a greater variation between actual and potential labour market experience.

Finally, to more formally estimate the extent to which selection on unobservables may be biasing our results we present the results of Rosenbaum's procedure for bounding the treatment effect estimates. ${ }^{4}$ The results, in Supplementary Appendix Table A9, suggest that robustness to hidden bias varies across the three labour market categories, as well as by gender. The finding of a strong negative effect of health shocks on male employment is the most robust to the possible presence of selection bias, with a critical level of gamma between 1.4 and 1.45. This effectively means that an unobserved confounder would have to change the odds ratio of treatment assignment by a factor of more than 1.4. For personal income and wages, the respective figures are 1.15 and 1.10. While the latter two are lower, given that the Rosenbaum bounds analysis presents a worst-case scenario, we don't consider that the main results we find for males are qualitatively impacted by this analysis. For females, the results are weaker, which also confirms the findings from the main results discussed above.

${ }^{4}$ DiPrete and Gangl (2004) present an excellent discussion of the Rosenbaum procedure in the context of a comparison with alternative Instrumental Variable techniques often used to circumvent the challenge of endogeneity. 


\section{Discussion and policy implications}

The empirical quest to establish the effects of individual health shocks on labour market outcomes is a relatively new one. While the stylised fact of association is beyond question, the nature of the relationship is complex and establishing the direction of causality places exacting demands on data. The literature to date has focused principally on more developed economies, has often concentrated on older working age groups in the context of retirement decisions and has been constrained by the absence of suitable longitudinal data sources. In this paper, exploring the Russian case for the first time, we find strong evidence that negative health shocks are associated with considerable reductions in wages and in total income but with more modest employment loss. The 19 rounds of longitudinal data that we explore, using difference-in-difference propensity score matching techniques allow us to establish, with a strong degree of confidence, that the relationship reflects the impact of health changes on labour market experience, rather than the reverse. We are therefore able to draw important conclusions and policy recommendations concerning the Russian labour market, the gender asymmetry in these relationships, the implications for inequality in Russia and the potential role that health care and social policies can play in mitigating risk.

The consensus view on the Russian labour market (Gimpelson, 2019) supposes that the flexibility is all on the price side, as characterised by stable levels of employment and unemployment on the one hand, and flexible, often volatile wages on the other hand. This model took root in the 1990s and, as Figure 1 shows, persists to the current time. Indeed, Russian employers have considerable flexibility, since the majority of the total remuneration is often paid as an adjustable 'premium' to the basic wage (Gimpelson and Kapeliushnikov, 2013). There are at least two ways of interpreting this in the current context. First, lower remuneration could reflect health-induced falls in productivity or second, reduced wages could simply reflect substantive adjustment in hours worked with reductions attributable to poor health, to lower productivity or to a disincentive for employers to engage in redundancies. No matter the explanation, these data suggest that policymakers need to consider interventions that can promote rapid recovery and reintegration into the labour market, whether that be through health care interventions, adjustments to the social safety net, or active labour market policies in concert with incentives for employers not to 'hide' unemployment. Some of these mechanisms around reduced productivity and health care utilisation merit further exploration.

Digging deeper into the results, we observe that males not only face more serious labour market and financial consequences than females regardless of the severity of the shock, but they also are more likely to report having experienced both positive and negative shocks than females. To explore this further, in Supplementary Appendix Table A10, we examine the association between $\mathrm{SAH}$, health shocks and more objective health indicators (recent ambulance call, missing work due to illness, EQ-5D index) available in the survey. We find, as expected, that levels of SAH are correlated with objective health indicators (all be it more strongly for males) but that health shocks are only associated with objective health events for males. This is consistent with the findings of Kaneva et al. (2018) and Gerry and Kaneva (2020) who, using the same RLMS-HSE data, find that females report the presence of chronic illness more often than males but that the adverse effect of chronic conditions are more serious for 
males. The latter of those two papers argues that, while females will report more minor conditions, males only report poorer levels of SAH if those conditions are associated with severe discomfort. This could explain why self-reported male health shocks are associated with objective health events, whereas female shocks are not.

There is an alternative, or perhaps complimentary explanation, that relates to the reasons why males only report more serious health effects. Evidence from elsewhere suggests that women pay more attention to their health, engage with health services more frequently and are cognisant of their minor ailments (Green and Pope, 1999; Ladwig et al., 2000; Vaidya et al., 2012, Thompson et al., 2016). Put differently, males fail to report less serious conditions because they delay help-seeking and ignore the presence of minor conditions, resulting in sharper and more severe deteriorations in health with associated consequences for the labour market.

Turning to the other socioeconomic and demographic covariates, the education results are striking in so far as they provide evidence of another return on human capital over and above those linked to employment, occupation and wages. That is, in Russia, those with higher levels of education are less vulnerable to the negative effects associated with health shocks. In policy terms, therefore, investing in education has additional welfare benefits in terms of the protection it offers the individual against labour market risk and the myriad positive aggregate level effects linked to higher productivity and reduced engagement with the welfare system. These data suggest that the cost (in lost wages and income) of health shocks is extremely high in Russia and attenuating that through realising that the returns to investment in education are higher than previously thought is important.

Consistent with these observations, we observe both that the effects of health shocks are considerably stronger for those in the lower half of the income distribution, particularly in terms of employment and income loss, and that those in the most senior occupational categories are also less vulnerable in the face of health shocks. Finally, the evidence of age asymmetry that we observe suggests that, while older workers are more vulnerable to employment loss, younger workers are more vulnerable to income and wage reductions. This is in line with the literature that links health shocks and premature retirement among older cohorts while price flexibility is felt more acutely among the younger part of the workforce. In sum, the conditioning effect of these socioeconomic and demographic variables has important implications for inequality in Russia, since those that are least advantaged to start with, are most vulnerable to the negative effects associated with health shocks.

Finally, of course, these findings have major implications for public health policies. Promoting policies that promote better health behaviours (as the Russian government has increasingly done during the last decade), encouraging interaction with the health service by increasing accessibility, particularly for males, and taking health more explicitly into account when designing policies intended to promote labour market participation and extend working lives may all have beneficial returns.

\section{Conclusion}

We have provided the first evidence for the Russian population demonstrating that adverse health shocks have a substantial negative effect on the probability of continuing employment, monthly income, and labour earnings. Consistent with what we know 
about the Russian labour market we find that the effect on wages and income is much stronger than on employment. The latter effect mirrors recent findings for the UK (Lenhart, 2019) and is slightly smaller than those presented by García-Gómez and López-Nicolás (2006) and García-Gómez (2011) for the Spanish population. In contrast, the effect on wages and income is much larger than that found in other studies, suggesting quite considerable knock-on effects for Russian workers, in terms of their loss of pensions, social benefits, bonuses, and other sources of income, over and above the losses to wage income.

These results, which quantify the labour market effects of health shocks in Russia for the first time, have important policy implications, not least because Russian population health is considerably below that predicted by its income level and therefore understanding how to attenuate the negative labour market consequences associated with health shocks is paramount. In particular, given the serious gender gap in health outcomes in Russia, the apparent labour market vulnerability of males, to health shocks, suggests an additional plausible category of explanation for understanding genderhealth dynamics in Russia.

\section{Supplementary data}

Supplementary data are available at Cambridge fournal of Economics online.

Conflicts of interest statement. None declared.

\section{Bibliography}

Angelini, V., Brugiavini, A. and Weber, G. 2009. Ageing and unused capacity in Europe: is there an early retirement trap?, Economic Policy, vol. 24, no. 59, 463-508.

$\mathrm{Au}, \mathrm{D}$. W. H., Crossley, T. F. and Schellhorn, M. 2005. The effect of health changes and long-term health on the work activity of older Canadians, Health Economics, vol. 14, no. 10, 999-1018.

Bound, J. and Burkhauser, R. V. 1999. Economic analysis of transfer programs targeted on people with disabilities, Handbook of Labor Economics, vol. 3, 3417-528.

Bound, J., Schoenbaum, M., Stinebrickner, T. R. and Waidmann, T. 1999. The dynamic effects of health on the labor force transitions of older workers, Labour Economics, vol. 6, no. 2, $179-202$.

Cook, L. J. 2015. Constraints on universal health care in the Russian federation: inequality, informality and the failures of mandatory health insurance reforms, fournal of Self-Governance and Management Economics, vol. 3, no. 4, 37-60.

Currie, J. and Madrian, B. C. 1999. Health, health insurance and the labor market, Handbook of Labor Economics, vol. 3, 3309-416.

Dano, A. M. 2005. Road injuries and long-run effects on income and employment, Health Economics, vol. 14, no. 9, 955-70.

Denisova, I. and Shapiro, J. 2013. Recent demographic developments in the Russian Federation, in Alexeev, M. and Weber, S. (eds), The Oxford Handbook of the Russian Economy, Oxford, Oxford University Press.

Devlin, N., Parkin, D. and Janssen, B. 2020. An introduction to EQ-5D instruments and their applications, pp. 1-22 in Methods for Analysing and Reporting EQ-5D Data, Cham, Springer. doi:10.1007/978-3-030-47622-9_1

DiPrete, T. A. and Markus, G. 2004 Assessing Bias in the Estimation of Causal Effects: Rosenbaum Bounds on Matching Estimators and instrumental Variables Estimation with Imperfect Instruments, WZB Discussion Paper, No. SP I 2004-101, Berlin, Wissenschaftszentrum Berlin für Sozialforschung (WZB). 
Disney, R., Emmerson, C. and Wakefield, M. 2006. Ill health and retirement in Britain: a panel data-based analysis, fournal of Health Economics, vol. 25, no. 4, 621-49.

European Central Bank Economic Bulletin. 2016. No. 6. https://www.ecb.europa.eu/pub/economicbulletin/html/eb201606.en.html (date last accessed 13 March 2021).

García-Gómez, P. 2011. Institutions, health shocks and labour market outcomes across Europe, fournal of Health Economics, vol. 30, no. 1, 200-13.

García-Gómez, P., Jones, A. M. and Rice, N. 2010. Health effects on labour market exits and entries, Labour Economics, vol. 17, no. 1, 62-76.

García Gómez, P. and López Nicolás, Á. 2006. Health shocks, employment and income in the Spanish labour market, Health Economics, vol. 15, no. 9, 997-1009.

García-Gómez, P., Van Kippersluis, H., O’Donnell, O. and Van Doorslaer, E. 2013. Long-term and spillover effects of health shocks on employment and income, fournal of Human Resources, vol. 48, no. 4, 873-909.

Gerry, C. J. 2021. Explaining the heterogeneity of health outcomes in post-Communist Europe, in Douarin, E. and Havrylyshyn O. (eds), The Palgrave Handbook of Comparative Economics, Cham, Palgrave Macmillan. doi:10.1007/978-3-030-50888-3_23

Gerry, C. J. and Kaneva, M. 2020. Adapting to the challenges of chronic non-communicable diseases: evidence from Russia, Applied Research in Quality of Life, vol. 16, 1537-53.

Gimpelson, V. 2019. The labor market in Russia, 2000-2017, pp. 466 in IZA World of Labor. doi:10.15185/izawol.466

Gimpelson, V. and Kapeliushnikov, R. 2013. Labor market adjustment: is Russia different?, in Alexeev, M. and Weber, S. (eds), The Oxford Handbook of the Russian Economy, Oxford, Oxford University Press.

Goryakin, Y. and Suhrcke, M. 2017. The impact of poor adult health on labor supply in the Russian Federation, The European Fournal of Health Economics, vol. 18, 361-72.

Green, C. A. and Pope, C. R. 1999. Gender, psychosocial factors and the use of medical services: a longitudinal analysis, Social Science Eo Medicine, vol. 48, no. 10, 1363-72.

Gupta, N. D., Kleinjans, K. J. and Larsen, M. 2015. The effect of a severe health shock on work behavior: evidence from different health care regimes. Social Science E Medicine, vol. 136, $44-51$.

Halla, M. and Zweimüller, M. 2013. The effect of health on earnings: quasi-experimental evidence from commuting accidents, Labour Economics, vol. 24, 23-38.

Idler, E. L. and Benyamini, Y. 1997. Self-rated health and mortality: a review of twenty-seven community studies. Fournal of Health and Social Behavior, 21-37.

Jones, A. M., Rice, N. and Roberts, J. 2010. Sick of work or too sick to work? Evidence on selfreported health shocks and early retirement from the BHPS, Economic Modelling, vol. 27, no. $4,866-80$.

Jones, A. M., Rice, N. and Zantomio, F. 2020. Acute health shocks and labour market outcomes: evidence from the post crash era. Economics \& Human Biology, vol. 36, 1-17.

Kaneva, M., Gerry, C. J. and Baidin, V. 2018. The effect of chronic conditions and multimorbidity on self-assessed health in Russia, Scandinavian fournal of Public Health, vol. 46, no. 8, 886-96.

Kaplan, G. A. and Camacho, T. 1983. Perceived health and mortality: a nine-year follow-up of the human population laboratory cohort, American fournal of Epidemiology, vol. 117, no. 3, 292-304.

Ladwig, K. H., Marten-Mittag, B., Formanek, B. and Dammann, G. 2000. Gender differences of symptom reporting and medical health care utilization in the German population, European Fournal of Epidemiology, vol. 16, no. 6, 511-8.

Lehmann, H. and Muravyev, A. 2012. Labour market institutions and labour market performance: what can we learn from transition countries?, Economics of Transition, vol. 20, no. 2, 235-69.

Lenhart, O. 2019. The effects of health shocks on labor market outcomes: evidence from UK panel data, The European fournal of Health Economics, vol. 20, no. 1, 83-98.

Lindeboom, M., Llena-Nozal, A. and van der Klaauw, B. 2016. Health shocks, disability and work, Labour Economics, vol. 43, 186-200.

Lindelow, M. and Wagstaff, A. 2005. Health Shocks in China: Are the Poor and Uninsured Less Protected? The World Bank. 


\section{Effect of health shocks on labour market outcomes in Russia}

Logvinenko, I. 2020. Authoritarian welfare state, regime stability, and the 2018 pension reform in Russia, Communist and Post-Communist Studies, vol. 53, no. 1, 100-16.

Lundborg, P., Nilsson, M. and Vikström, J. 2015. Heterogeneity in the impact of health shocks on labour outcomes: evidence from Swedish workers, Oxford Economic Papers, vol. 67, no. 3, 715-39.

Mitra, S., Palmer, M., Mont, D. and Groce, N. 2016. Can households cope with health shocks in Vietnam?, Health Economics, vol. 25, no. 7, 888-907.

OECD. 2020. Alcohol Consumption (Indicator). doi: 10.1787/e6895909-en (date last accessed 08 August 2020).

OECD. 2020. Daily Smokers (Indicator). doi: 10.1787/1ff488c2-en (date last accessed 08 August 2020).

OECD. 2020. Life Expectancy at Birth (Indicator). doi: 10.1787/27e0fc9d-en (date last accessed 08 August 2020).

OECD. 2020. Working Age Population (Indicator). doi: 10.1787/d339918b-en (date last accessed 08 August 2020).

Pfarr, C., Schmid, A. and Schneider, U. 2012. Reporting heterogeneity in self-assessed health among elderly Europeans, Health Economics Review, vol. 2, no. 1, 21.

Shmueli, A. 2003. Socio-economic and demographic variation in health and in its measures: the issue of reporting heterogeneity, Social Science \& Medicine, vol. 57, no. 1, 125-34.

Slonimczyk, F. and Gimpelson, V. 2015. Informality and mobility: evidence from Russian panel data, Economics of Transition, vol. 23, no. 2, 299-341.

Slonimczyk, F. and Yurko, A. 2014. Assessing the impact of the maternity capital policy in Russia, Labour Economics, vol. 30, 265-81.

Sorvachev, I. and Yakovlev, E. 2020. Short- and Long-Run Effects of a Sizable Child Subsidy: Evidence from Russia, IZA Discussion Papers No. 13019, February 2020. Bonn, Germany.

Thompson, A. E., Anisimowicz, Y., Miedema, B., Hogg, W., Wodchis, W. P. and AubreyBassler, K. 2016. The influence of gender and other patient characteristics on health careseeking behaviour: a QUALICOPC study, BMC Family Practice, vol. 17, no. 1, 38.

Trevisan, E. and Zantomio, F. 2016. The impact of acute health shocks on the labour supply of older workers: evidence from sixteen European countries, Labour Economics, vol. 43, 171-85.

Vaidya, V., Partha, G. and Karmakar, M. 2012. Gender differences in utilization of preventive care services in the United States, fournal of Women's Health, vol. 21, no. 2, 140-5.

World Bank. 2020. Life Expectancy at Birth (Indicator). https://data.worldbank.org/ (date last accessed 23 October 2020).

World Health Organisation. 2018. Noncommunicable Diseases Country Profiles -Russia. https:// www.who.int/nmh/countries/2018/rus_en.pdf?ua=1 (date last accessed 3 March 2021).

Zucchelli, E., Jones, A. M., Rice, N. and Harris, A. 2010. The effects of health shocks on labour market exits: evidence from the HILDA survey, Australian fournal of Labour Economics, vol. 13, no. 2, 191.

Zwysen, W. 2015. The effects of father's worklessness on young adults in the UK, IZA fournal of European Labor Studies, vol. 4, no. 1, 2. 
